\title{
SOBRE LA LEGITIMACIÓN EN LA CAUSA
}

\author{
Álvaro EduARdo ORdoñEZ GuZMÁN*
}

Recibido: 6 de octubre de 2017 - Aceptado: 15 de noviembre de 2017

DOI: $10.24142 /$ raju.v12n25a8

\section{Resumen}

Con ocasión de los cambios legislativos establecidos por la ley 1395 de 2010 y la ley 1564 de 2012, la legitimación en la causa, determinada como una aptitud para la participación dentro del proceso, requiere de un análisis detenido en cuanto a su comprensión, en aras de evitar una finalización prematura e injustificada del proceso que sea, por ende, lesiva para las partes.

Palabras clave: legitimación en la causa, sentencia anticipada, presupuestos axiológicos, presupuestos materiales.

\section{ON THE LEGITIMATION IN THE CAUSE}

\section{Abstract}

On the occasion of the legislative changes established by Law 1395 of 2010 and Law 1564 of 2012, the legitimacy in the case, established as an aptitude for participation in the process, requires a careful analysis

Abogado Universidad de Medellín, Magíster Universidad de Medellín, Especialista en Derecho Procesal Contemporáneo de la misma universidad y Especialista en Derecho de los Negocios de la Universidad Externado de Colombia. Correo electrónico: alvarord1@ @otmail.com 
in terms of its understanding, for the sake of to avoid a premature and unjustified termination of the process that is, therefore, harmful to the parties.

Keywords: Legitimation in the cause, anticipated sentence, axiological budgets, material assumptions. 


\section{INTRODUCCIÓN}

Existe un concepto procesal que amerita un estudio en cuanto a su esencia y efectos, dado que respecto a él se han elaborado nociones que pueden repercutir en el desarrollo mismo de un proceso jurisdiccional, conllevando, incluso, a su finalización en una etapa incipiente. Se hace alusión a la legitimación en la causa, acogida en este escrito en su arista ordinaria, la cual ha sido abordada desde una perspectiva procesal y otra sustancial o material. De ahí que resulte trascendental la posición que se asuma frente a las posibilidades conceptuales que se han desprendido de la figura aludida, dado que, de esto, ante las variantes legislativas actuales, dependerá o no la finalización del proceso en una etapa temprana del mismo sin que se hayan agotado etapas significativas de debate.

La ley 1395 de 2010, en su artículo 6, estableció que: "también podrán proponerse como previas las excepciones de cosa juzgada, transacción, caducidad de la acción, prescripción extintiva y falta de legitimación en la causa. Cuando el juez encuentre probada cualquiera de estas excepciones, lo declarará mediante sentencia anticipada" (República de Colombia, 2010a).

A su turno, la ley 1564 de 2012, Código General del Proceso, en su artículo 278, prevé la posibilidad de una sentencia anticipada, entre otras razones, "cuando se encuentre probada la cosa juzgada, la transacción, la caducidad, la prescripción extintiva y la carencia de legitimación en la causa" (República de Colombia, 2012a).

Así las cosas, y ante la ausencia de una definición por parte de la legislación, respecto de lo que debe considerarse como legitimación en la causa, resulta evidente la necesidad de una reflexión sobre la figura procesal y sus repercusiones.

\section{LA LEGITIMACIÓN EN LA CAUSA}

De cara a la legitimación en la causa se tiene que esta indaga quiénes pueden ser parte en un proceso, "en rigor, quién debe sufrir o gozar de los efectos de la sentencia de mérito" (Alvarado, 2005, p. 95).

Según el tratadista Hernando Devis (2009), con la legitimación en la causa:

se trata de saber cuándo el demandante tiene derecho a que se resuelva sobre las determinadas pretensiones contenidas en la demanda y 
cuándo el demandado es la persona frente a la cual debe pronunciarse esa decisión, y si demandante y demandado son las únicas personas que deben estar presentes en el juicio para que la discusión sobre la existencia del derecho material o relación jurídico-material pueda ser resuelta, o si, por el contrario existen otras que no figuran como demandantes ni demandados. Por ello se trata de otra condición para que haya sentencia de mérito o fondo (p. 305).

Se debe advertir que la legitimación en la causa puede ser analizada como legitimación ordinaria (coincidencia de la relación sustancial y de la relación procesal) y como legitimación extraordinaria (ausencia de la anterior coincidencia). En este escrito se emprenderá el estudio concerniente a la primera.

La legitimación en la causa ordinaria: sobre la legitimación en la causa, desde la perspectiva ordinaria, explica la doctora Beatriz Quintero (2000) que "nadie puede, en nombre propio, pretender o ser demandado a contradecir en proceso, resistir a una pretensión, sino por una relación, de la cual se atribuya o se le atribuya a él la subjetividad activa o pasiva" (p. 371).

Desde la acepción ordinaria de la legitimación se alude a la existencia de una titularidad procesal y a otra sustancial. Como lo explana la doctrinante en cita:

pretender o ser demandado a contradecir en proceso, es terminología que inconfundiblemente alude a la subjetividad de la relación procesal: ser parte en sentido formal, entonces, llegar al proceso en cualquiera de las dos posiciones posibles, como demandante o como demandado. La otra noción corresponde a la subjetividad de la relación sustancial que subyazca al proceso, a la titularidad del derecho discutido, a la titularidad del derecho sustancial (Quintero, 2000, p. 371).

En torno a dicho concepto se han tejido dos posturas contradictorias. Una primera posición asume la figura desde una visión vinculada al mérito o sustancia de la pretensión. La segunda perspectiva la identifica con la forma o la aptitud.

- La legitimación en la causa desde una postura material o sustancial

Para los adeptos a la primera postura, la legitimación en la causa es equiparable con la titularidad del derecho sustancial que subyace a la relación procesal entre actor y opositor. De esta forma, se cumple con la legiti- 
mación en la causa siempre que se acredite la coincidencia de la titularidad de la relación sustancial con la procesal. La legitimación estará vinculada a los denominados presupuestos axiológicos de la pretensión, en lo que al aspecto subjetivo se refiere. En el evento de no acreditarse la titularidad sustancial del actor o del opositor, es perfectamente posible que se emita una sentencia de mérito, pero que la misma sea desfavorable por la ausencia de legitimación en la causa.

Como puede observarse, esta visión del concepto atiende a los presupuestos axiológicos de lo pretendido, conocidos también como los presupuestos de la sentencia favorable. En otras palabras, desde esta visión se aludiría a aquellos aspectos que deben estar acreditados dentro del proceso para que el actor acceda a una tutela concreta en sentido positivo o favorable. $\mathrm{Al}$ respecto, se puede anotar lo siguiente:

Para que una pretensión logre ser estimada debe fundarse en unos hechos que correspondan al supuesto normativo de la norma sustancial que a la vez consagra como consecuencia jurídica la aspiración del pretensionante, o sea, lo que pide, el petitum. Esos hechos, en correspondencia con el supuesto normativo abstracto, son los elementos axiológicos de cada pretensión. Los hechos que el demandante tiene que alegar y probar para obtener una sentencia que estime su pretensión. De esta manera se pone en evidencia la diferencia esencial que se ofrece entre los elementos axiológicos de la pretensión y cualquiera de los requisitos de forma del proceso, aun de los presupuestos materiales de la sentencia de fondo, que pudieran considerarse como los más próximos conceptualmente. Aquellos son presupuestos de una sentencia favorable. Estos lo son de una sentencia de mérito, en cualquiera de los sentidos, estimatoria o desestimatoria de la pretensión (Quintero, 2000, pp. 400-401).

Desde esta visión sustancial, la carencia de legitimación no impide el proferimiento de una sentencia de fondo, solo que será desestimatoria para el actor, al no estar demostrado el mérito de esta (Quintero, 2000). Sobre el particular, expone la tratadista colombiana:

La primera postura entiende que la decisión sobre legitimación es una decisión sobre la titularidad del derecho, sobre el derecho mismo, sobre uno de los elementos axiológicos de la pretensión y por eso el proveído correspondiente es una sentencia de mérito: negando la 
legitimación se estará negando el derecho sustancial y decidiendo sobre la ausencia de legitimación se estará decidiendo en el fondo del proceso (Quintero, 2000, p. 369).

Sobre el tópico, Chiovenda ha puntualizado:

Preferimos nuestra antigua denominación de legitimatio ad causam (legitimación para obrar): con esta entiéndase la identidad de la persona del actor con la persona a la cual la ley concede la acción (legitimación activa) y la identidad de la persona del demandado con la persona contra la cual es concedida la acción (legitimación pasiva) (Chiovenda, 1922, p. 178).

La Corte Suprema de Justicia, en su Sala de Casación Civil, se adhiere a esta visión, tal y como puede corroborarse en múltiples providencias.

En efecto, el órgano de cierre civil ha expuesto:

Preciso es notar cómo la legitimación en la causa, ha dicho insistentemente la Corte, es cuestión propia del derecho sustancial y no del procesal, por cuanto alude a la pretensión debatida en el litigio y no a los requisitos indispensables para la integración y desarrollo válido de este. Por eso, su ausencia no constituye impedimento para resolver de fondo la litis, sino motivo para decidirla adversamente, pues ello es lo que se aviene cuando quien reclama un derecho no es su titular o cuando lo aduce ante quien no es el llamado a contradecirlo, pronunciamiento ese que, por ende, no solo tiene que ser desestimatorio sino con fuerza de cosa juzgada material para que ponga punto final al debate, distinto de un fallo inhibitorio carente de sentido lógico por cuanto tras apartarse de la validez del proceso siendo este formalmente puro, conduce a la inconveniente práctica de que quien no es titular del derecho insista en reclamarlo o para que siéndolo en la realidad lo aduzca nuevamente frente a quien no es el llamado a responder.

Concretando su criterio sobre el punto, la Corte hizo la siguiente exposición:

"Según concepto de Chiovenda, acogido por la Corte, la legitimatio ad causam consiste en la identidad de la persona del actor con la persona a la cual la ley concede la acción (legitimación activa) y la identidad de la persona del demandado con la persona contra la cual es concedida la acción (legitimación pasiva)" (Instituciones de Derecho Procesal Civil, I, 185). 
Conviene desde luego advertir, para no caer en el error en que incurrió el Tribunal que cuando el tratadista italiano y la Corte hablan de "acción" no están empleando ese vocablo en el sentido técnico procesal, esto es como el derecho subjetivo público que asiste a toda persona para obtener la aplicación justa de la ley a un caso concreto, y que tiene como sujeto pasivo al Estado, sino como sinónimo de "pretensión", que se ejercita frente al demandado. Para que esa pretensión sea acogida en la sentencia es menester, entre otros requisitos, que se haga valer por la persona en cuyo favor establece la ley sustancial el derecho que se reclama en la demanda, y frente a la persona respecto de la cual ese derecho puede ser reclamado. De donde se sigue que lo concerniente a la legitimación en la causa es cuestión propia del derecho sustancial y no del derecho procesal, razón por la cual su ausencia no constituye impedimento para desatar en el fondo el litigio sino motivo para decidirlo en forma adversa al actor. Si el demandante no es titular del derecho que reclama o el demandado no es persona obligada, el fallo ha de ser adverso a la pretensión de aquel, como acontece cuando reivindica quien no es el dueño o cuando este demanda a quien no es poseedor.

Por cuanto una de las finalidades de la función jurisdiccional es la de componer definitivamente los conflictos de interés que surgen entre los miembros de la colectividad, a efecto de mantener la armonía social, es deber del juez decidir en el fondo las controversias de que conoce, a menos que le sea imposible hacerlo por existir impedimentos procesales, como ocurre cuando faltan los presupuestos de capacidad para ser parte o demanda en forma. La falta de legitimación en la causa de una de las partes no impide al juez desatar el litigio en el fondo, pues es obvio que si se reclama un derecho por quien no es su titular o frente a quien no es el llamado a responder, debe negarse la pretensión del demandante en sentencia que tenga fuerza de cosa juzgada material, a fin de terminar definitivamente ese litigio, en lugar de dejar las puertas abiertas, mediante un fallo inhibitorio para que quien no es titular del derecho insista en reclamarlo indefinidamente, o para que siéndolo lo reclame nuevamente de quien no es persona obligada, haciéndose en esa forma nugatoria la función jurisdicción cuya característica más destacada es la de ser definitiva (CXXXVIII, 364/65). (República de Colombia, 1995).

En sentencia del 12 de junio de 2001, la Corte reiteró la anterior posición sobre la legitimación en la causa (República de Colombia, 2001).

Del mismo modo, en decisión del 1 de julio de 2008, el Tribunal de Casación estableció: 
En reiteradas oportunidades ha dicho la Corte que la legitimación en causa, esto es, el interés directo, legítimo y actual del "titular de una determinada relación jurídica o estado jurídico” (U. Rocco, Tratado de derecho procesal civil, T. I, Parte general, $2^{\mathrm{a}}$ reimpresión, Temis-Depalma, Bogotá, Buenos Aires, 1983, pp. 360), es cuestión propia del derecho sustancial, atañe a la pretensión y es un presupuesto o condición para su prosperidad. Por tal motivo, el juzgador debe verificar la legitimatio ad causam con independencia de la actividad de las partes y sujetos procesales al constituir una exigencia de la sentencia estimatoria o desestimatoria, según quien pretende y frente a quien se reclama el derecho sea o no su titular (República de Colombia, 2008).

Lo anterior fue iterado en providencias del 14 de octubre de 2010 y del 13 de octubre de 2011, destacando que

es obvio que si se reclama un derecho por quien no es su titular o frente a quien no es el llamado a responder, debe negarse la pretensión del demandante en sentencia que tenga fuerza de cosa juzgada material, a fin de terminar definitivamente ese litigio, en lugar de dejar las puertas abiertas, mediante un fallo inhibitorio para que quien no es titular del derecho insista en reclamarlo indefinidamente, o para que siéndolo lo reclame nuevamente de quien no es persona obligada, haciéndose en esa forma nugatoria la función jurisdicción cuya característica más destacada es la de ser definitiva (casación de 3 de junio de 1971, CXXXVIII, litis. 364 y siguientes) (República de Colombia, 2011).

Así mismo, en sentencias del 31 de agosto de 2012, 26 de julio de 2013, 22 de abril de 2014 y 23 de octubre de 2015, entre otras, la Corte reafirmó la citada posición.

En definitiva, desde esta postura la legitimación en la causa no será un asunto que pueda advertirse fácilmente desde el inicio del proceso, sino que ameritará un debate probatorio en aras de acreditar la titularidad sustancial de quien reclama y de quien es reclamado en el proceso.

Vinculándose al mérito de lo pretendido, la demostración de la coincidencia de la titularidad sustancial con la procesal se advertirá en la sentencia de fondo o mérito y se circunscribirá a su vez a la carga de probar por parte del actor, dado que, como ya se indicó, estará adherida a los presupuestos axiológicos necesarios para una sentencia de mérito favorable. 
En tal contexto, la ausencia de legitimación en la causa, prevista como la no acreditación de la coincidencia de titularidades, no impedirá una sentencia que resuelva el mérito de lo reclamado por el pretendiente, solo que si no se acredita la coexistencia de titularidades (sustancial y procesal) la sentencia devendrá desestimatoria por carencia de legitimación en la causa, por cuanto, desde esta tesis, el instituto resulta necesario para cumplir con los presupuestos de la sentencia de mérito favorable.

- La legitimación en la causa desde una postura formal o procesal

Los defensores de la segunda postura diferencian entre el fondo de lo pretendido y la aptitud, legitimación, para intervenir en el proceso, aseverando que se trata de un asunto de forma y no de mérito. Desde esta óptica debe afirmarse una titularidad sustancial que resulte simultánea con la procesal, sin que devenga trascendental para la acreditación del requisito la demostración de la concurrencia sustancial con la procesal. Se indica asî que no es un asunto probatorio, sino de afirmación o aseveración. Solo debe manifestarse una equivalencia entre la relación sustancial y la procesal, sin que sea necesario probar la titularidad de dicha relación sustancial al interior del proceso. Al respecto, explica la tratadista Quintero (2000):

existen dos titularidades y la coincidencia de ellas en cada sujeto y en cada polo de la relación, activo o pasivo, tiene que ser afirmada en la demanda para que se satisfaga el requisito de la legitimación ordinaria. Se insiste: basta con que sea afirmada sin que importe para nada su verdad o realidad jurídica [...] la afirmación de titularidades de manera que coincidan los sujetos de la pretensión formal y los de la relación sustancial es suficiente, como ya se anotó, al cumplimiento del presupuesto; pero es también condición necesaria; sin esa afirmación en la demanda o con una afirmación de titularidades que no coincidan no se satisface el presupuesto de legitimación (pp. 371-372).

Desde esta posición, la legitimación representa un presupuesto para que se pueda dictar sentencia de fondo, no en sentido favorable, sino en cualquier sentido. Es decir, que la ausencia de legitimación en la causa lleva a que no resulte viable emitir un fallo que se pronuncie sobre el mérito de lo pretendido. La profesora Quintero (2000) indica lo siguiente:

En la postura formal, en cambio, se puntualiza que el concepto de legitimación hace referencia a la pretensión procesal y mira tan solo 
a la relación sustancial subyacente como a un punto de comparación para adecuar la subjetividad formal a la subjetividad material, a la legitimación sustancial, pudiera decirse, pero con el efecto formal de impedir la sentencia de fondo (p. 369).

\section{REPERCUSIONES DE LAS POSTURAS DE CARA A LOS CAMBIOS NORMATIVOS}

El código general del proceso: como ya se anotó, con la ley 1395 de 2010 se introdujo la posibilidad de una sentencia anticipada en el evento de no constatarse la legitimación en la causa. Esta posibilidad fue recogida por la nueva legislación procesal, ley 1564 de 2012, mejor conocida como el Código General del Proceso. Dicho estatuto señala como una de las causales para emitir sentencia, en cualquier momento, la falta de legitimación en la causa. En efecto, el artículo 278 del estatuto referido expresa que

en cualquier estado del proceso, el juez deberá dictar sentencia anticipada, total o parcial, en los siguientes eventos: [...] 3. Cuando se encuentre probada la cosa juzgada, la transacción, la caducidad, la prescripción extintiva y la carencia de legitimación en la causa (República de Colombia, 2012a).

Lo anterior resulta significativo toda vez que, según la postura que se asuma respecto a la legitimación en la causa, podrá afectarse el devenir propio del proceso.

Es necesario advertir que el supuesto normativo no establece un escenario claro de aplicación, dejando al juez con una posibilidad excesivamente abierta para proferir sentencia "en cualquier estado del proceso". Además, nótese que la regla no diferencia si se trata de una legitimación formal o material, ni delimita la manera en la que el director del proceso puede hacer uso de esa herramienta, pudiendo llegar a extremos absolutamente lesivos para las partes.

A propósito, se tiene que la norma no expresa si la posibilidad de dictar sentencia en cualquier momento del proceso solo es viable cuando no existe afirmación de la coexistencia de las relaciones procesales y sustanciales, o si solo es posible cuando exista prueba referente a que la parte actora o la pasiva no son los titulares de la relación material que se debate en un 
proceso. Tampoco resuelve si en este último evento debe agotarse o no un mínimo de etapa probatoria para tal fin.

En ese contexto, podría elucubrarse que la norma solo alude a la legitimación en la causa desde su arista formal, por cuanto, en primer lugar, no indica que necesariamente se deba dictar sentencia de fondo, lo que habilita la posibilidad de la sentencia inhibitoria, que es el resultado de la carencia de legitimación en la causa, entendida desde un punto de vista netamente procesal; en segundo lugar, salvo la prescripción extintiva, el grupo de circunstancias que habilita el numeral 3 del artículo en mención está vinculado a la posibilidad o no de dictar sentencia de mérito.

Adviértase que excepciones como la cosa juzgada, la transacción y la caducidad, cuando se configuran, impiden que el juez pueda emitir una sentencia de fondo.

No obstante, como ya se advirtió, la norma no diferencia si se trata de legitimación en la causa material o formal, sino que dejó abierto el concepto. Esta situación posibilita el surgimiento de diversas dificultades a la hora de aplicar la opción que expone la norma, de cara a su oportunidad, requisitos, etc.

Una de esas dificultades puede evidenciarse en escenarios en los que el juez, al ser partidario de una legitimación en la causa que acoja el instituto desde una postura material, decida resolver el proceso, no bajo la totalidad de pruebas recaudadas o a recaudar, sino con apoyo en un incipiente acervo probatorio, allegado en las etapas preliminares del proceso y, por ende, no completo.

Una postura como la anterior podría derivar en una sentencia temprana y acrítica sobre lo debatido, incurriendo en el riesgo de una carencia de análisis suficiente de todo un material probatorio que debía recaudarse y, por esta razón, se vulneraría el derecho fundamental a un debido proceso. Piénsese un evento en el que el juez, ante la sola respuesta del demandado y las escasas pruebas que allegue en su contestación, decida proferir inmediatamente fallo sobre lo pretendido, sin permitir agotar un debate probatorio y sin recaudar la totalidad de elementos de confirmación que estarían llamados a conformar el conjunto probatorio correspondiente.

En este punto debe indicarse que, de esa forma, se podría configurar un defecto fáctico, en tanto que este es

una de las causales específicas de procedibilidad de la acción de tutela contra providencias judiciales. Sin embargo, para que se configure 
este vicio es necesario que el operador judicial profiera una decisión sin contar con el necesario y adecuado respaldo probatorio, lo que trae como directa consecuencia una distorsión entre la verdad jurídica o procesal y la material, situación en la que, sin duda, deja de realizarse el inexorable deber atribuido a los jueces de impartir justicia (República de Colombia, 2016).

Por lo anterior, teniendo en cuenta las posibilidades normativas, se requiere que la legitimación en la causa se estudie en cada caso concreto de una forma crítica, para efectos de evitar vulneraciones al interior del proceso cuando el juez decida hacer uso de ella.

Una propuesta para evitar vulneraciones a la hora de entender el artículo 278 del Código General del Proceso, es comprender que en dicha norma solo se alude a la posibilidad de una sentencia anticipada si se confronta la carencia de la misma desde una perspectiva formal, toda vez que de entenderse el concepto desde la visión material, sin haberse recaudado la totalidad de elementos de prueba y sin que se trate de la etapa procesal correspondiente para su valoración (la sentencia), podrían cercenarse los derechos de las partes, por cuanto que, como se ha advertido, en una etapa absolutamente temprana y según criterio incipiente del juez, se definiría la titularidad sustancial de las partes sin agotarse un mínimo de oportunidad probatoria. Por eso, de entenderse el concepto desde una visión material, la sentencia solo deberá proferirse una vez agotado el correspondiente debate probatorio sobre la coincidencia o no de las titularidades de las relaciones sustanciales y procesales.

\section{REFERENCIAS}

Alvarado, A. (2005). Introducción al estudio del derecho procesal. Buenos Aires: Rubinzal Culzoni.

Chiovenda, G. (1922). Principios de Derecho Procesal Civil, Tomo I. Madrid: Reus.

Devis, H. (2009). Nociones generales de Derecho Procesal Civil. Bogotá: Temis.

Quintero, B. (2000). Teoría general del proceso. Bogotá: Temis.

República de Colombia (1995). Sala de Casación Civil. Sentencia del 14 de agosto de 1995. Expediente No. 4268. Recuperado de http://materiacontractual.blogspot.com.co/2011/08/exp-4268-14-ago-1995.html 
República de Colombia (2001). Sala de Casación Civil. Sentencia del 12 de junio de 2001. Expediente No. 6050. Recuperado de https://corte-suprema-justicia.vlex.com.co/vid/552526254

República de Colombia (2008). Sala de Casación Civil. Sentencia del 1 de julio de 2008. Expediente No. 11001-3103-033-2001-06291-01. Recuperado de http://www.globalsaleslaw.org/content/api/cisg/urteile/2245.pdf

República de Colombia (2010a). Ley 1395 de 2010. Recuperado de http://www.secretariasenado.gov.co/senado/basedoc/ley_1395_2010.html

República de Colombia (2010b). Sala de Casación Civil. Sentencia del 14 de octubre de 2010. Expediente exp. 2001-00855-01. Recuperado de www. cortesuprema.gov.co/.../Sentencia-de-simulación-del-13-de-octubre-de-2011. pdf

República de Colombia(2011). Sala de Casación Civil. Sentencia del 13 de octubre de 2011. Expediente 11001-3103-032-2002-00083-01. Recuperado de http://www.cortesuprema.gov.co/corte/wp-content/uploads/2017/03/ Sentencia-de-simulaci\%C3\%B3n-del-13-de-octubre-de-2011.pdf

República de Colombia (2012a). Ley 1564 de 2012. Recuperado de http://www.secretariasenado.gov.co/senado/basedoc/ley_1564_2012.html

República de Colombia (2012b). Sala de Casación Civil. Sentencia del 13 de agosto de 2012. Expediente 11001-31-03-035-2006-00403-01. Recuperado de https://corte-suprema-justicia.vlex.com.co/vid/-399364374

República de Colombia (2013). Sala de Casación Civil. Sentencia del 26 de julio de 2013. Expediente 05001-31-03-009-2004-00263-01. Recuperado de https://www.notinet.com.co/pedidos/00263.doc

República de Colombia (2014). Sala de Casación Civil. Sentencia del 22 de abril de 2014. Expediente SC4809-2014 0500131030112000-00368-01. Recuperado de www.cortesuprema.gov.co/.../gabr2014/SENTENCIAS\%20 ABRIL\%202014/SC4809

República de Colombia (2015). Sala de Casación Civil. Sentencia del 23 de octubre de 2015. Expediente 11001-31-03-039-2010-00490-01. Recuperado de https://cdn.actualicese.com/normatividad/2015/Sentencias/S-SC-1465815.pdf

República de Colombia (2016) Corte Constitucional (2016). Sentencia SU-489. Recuperado de http://www.corteconstitucional.gov.co/relatoria/2016/SU489-16.htm 